\title{
The Effects of BR003 on Memory and Cell Proliferation in the Dentate Gyrus of Rat Hippocampus
}

\author{
Myung Sook OH, ${ }^{a}$ Chan PARK, ${ }^{b}$ Youngbuhm HuH, ${ }^{b}$ Hong-Yeoul KIM, ${ }^{c}$ Hocheol KIM, ${ }^{a}$ \\ Hyung-Min KIM, ${ }^{a}$ Hyunsu BAE, ${ }^{a}$ Duk Kyun AhN, ${ }^{d}$ Wan-Su PARK, ${ }^{a}$ and Seong Kyu PARK ${ }^{*, a}$ \\ ${ }^{a}$ College of Oriental Medicine, Kyung Hee University; ${ }^{b}$ College of Medicine, Kyung Hee University; ${ }^{c}$ Institute of Oriental \\ Medicine, Kyung Hee University; 1 Hoegi-dong, Dongdaemun-gu, Seoul 130-701, Korea: and Jaseng Research Institute \\ of Bio-technology and Bioscience; Jin Deuk Building 202, 636-10 Sinsa-dong, Kangnam-gu, Seoul 135-896, Korea. \\ Received August 11, 2005; accepted December 26, 2005
}

BR003 is a multi-herbal formula that contains twelve medicinal herbs. We investigated the effects of oral administration of BR003 to Wistar rats on (a) learning and memory using a passive avoidance test and (b) cell proliferation in the dentate gyrus (DG) of the hippocampus using immunohistochemical analysis of 5-bromo-2-deoxyuridine (BrdU) expression. In the passive avoidance test, the retention time of the BR003-treated group was significantly longer than that of the control group $(182.64 \pm 39.88 v s .73 .08 \pm 29.30 \mathrm{~s}$, respectively; $n=11 ; p<0.05)$. There were significantly more BrdU-immunoreactive cells in the DG in the BR003-treated group than in the control group $(1281.07 \pm 151.16$ vs. $818.01 \pm 132.98$ cells per $D G$, respectively; $n=11 ; p<0.05)$. These results suggest that the administration of BR003 not only improves learning and memory but also increases cell proliferation in the DG of the rat hippocampus.

Key words BR003; memory; cell proliferation; passive avoidance test; 5-bromo-2-deoxyuridine

Memory involves encoding, storing, and recalling information. Short-term memory (STM) lasts for minutes, whereas long-term memory (LTM) lasts for hours, days, weeks, and even years. ${ }^{1)}$ The hippocampus is crucial for learning and memory in humans and animals. The hippocampus converts short-term memories into long-term memories and plays a pivotal role in encoding, consolidating, and retrieving associations that are responsible for episodic memory. ${ }^{2,3)}$ The hippocampus and the entorhinal cortex both participate in the formation and expression of memory in the one-trial step-down inhibitory avoidance task in rats. ${ }^{4)}$

In mammals, neurons are produced early in development; however, in the dentate gyrus (DG) of the hippocampal formation, granule cell neurons are produced throughout adulthood. ${ }^{5,6)}$ Neurogenesis in the DG is a multi-step process that originates within the subgranular zone of the hippocampus. ${ }^{7}$ New neurons produced from precursor cells in the subgranular zone extend axonal projections and express several markers that are specific to neurons. ${ }^{8,9)}$ New neurons in the DG of the hippocampus were recently shown to be integrated functionally into appropriate neuronal circuits, and hippocampusmediated learning and memory may be related to the generation of new neurons in the adult DG. ${ }^{10,11)}$

Many herbal drugs used in traditional medicine in Asia are generally combined in the form of multi-herbal formulas to create novel therapeutic agents that are more effective than the administration of the individual herbs. ${ }^{12)}$ BR003 is a new formula that has been prescribed recently to enhance memory. BR003 comprises twelve medicinal herbs: Acanthopanacis Senticosi Radix (Acanthopanax senticosus HARms, Araliaceae); Schizandrae Fructus (Schisandra chinensis BAILl., Magnoliaceae); Ginkgo Folium (Ginkgo biloba L., Ginkgoaceae); Ginseng Radix (Panax ginseng Meyer, Araliaceae); Astragali Radix (Astragalus membranaceus Bunge, Leguminosae); Atractylodis Rhizoma (Atractylodes macrocephala KoIDz., Compositae); Poria (Poria cocos Wolf, Polyporaceae); Ziziphi Semen (Zizyphus jujuba MiLl., Rhamnaceae); Longanae Arillus (Euphoria Longan Steud., Sapindaceae); Angelicae Sinensis Radix (Angelica sinensis Diels, Umbelliferae); Polygalae Radix (Polygala tenuifolia WILlD., Polygalaceae); and Glycyrrhizae Radix (Glycyrrhiza uralensis FISCH., Leguminosae).

Even though many herbal remedies are used in traditional medicine to improve memory and cognitive function, whether herbal remedies enhance cell proliferation within the hippocampus is largely unknown. ${ }^{13)}$ In this study, we investigated the effect of BR003 on learning and memory in rats and on cell proliferation in the DG of rat hippocampus.

\section{MATERIALS AND METHODS}

Plant Materials and Preparation of BR003 Individual dried herbs were purchased from Wonkwang Herbal Drug Co. Ltd. (Seoul, Korea). BR003 comprised 14\% each Acanthopanacis Senticosi Radix, Schizandrae Fructus, and Ginkgo Folium; 7\% each Ginseng Radix, Astragali Radix, Atractylodes Rhizoma, Poria, Ziziphi Semen, Longanae Arillus, Angelicae Sinensis Radix, and Polygalae Radix; and 2\% Glycyrrhizae Radix. BR003 extract was prepared by decocting $570 \mathrm{~g}$ of the dried prescription herbs with 101 of boiling distilled water for $2 \mathrm{~h}$. The extract was filtered and lyophilized to yield $126 \mathrm{~g}(22 \%)$ of powder, which was kept at $4{ }^{\circ} \mathrm{C}$.

Animals and Administration of BR003 Six-week-old male Wistar rats were purchased from Japan SLC Inc. (Shizuoka, Japan). The animals were housed in a specific pathogen-free environment with a 12/12 h light/dark cycle at the Center for Laboratory Animal Care and Use at Kyung Hee University. Animals had free access to standard rodent pellets (Purina Inc., Korea) and water. After $10 \mathrm{~d}$ of adaptation to the environment, the rats $(n=11)$ were administered BR003 $(2.0 \mathrm{~g} / \mathrm{kg} / \mathrm{d}$, p.o. $)$ for $16 \mathrm{~d}$. Control rats $(n=11)$ received vehicle only. During the treatment period, food intake was measured everyday and body weights were monitored 
every second day.

Passive Avoidance Test A modified passive avoidance test was used to assess the effect of BR003 on learning and memory. ${ }^{14)}$ The step-through passive avoidance apparatus contained one light chamber equipped with an illuminator and one dark chamber. The chambers were separated by a guillotine door. During the training phase, a rat was placed in the light chamber with the door open. When the rat entered the dark chamber, the guillotine door was closed immediately. After being allowed to explore the dark chamber for $1 \mathrm{~min}$, the rat was removed from the apparatus and placed in its cage. This training protocol was repeated until the rat entered the dark chamber within $20 \mathrm{~s}$ of being placed in the light chamber. Animals that did not enter the dark chamber were excluded from the experiment. At $24 \mathrm{~h}$ after training, the rat was placed in the light chamber. Immediately after the rat entered the dark chamber (all four paws), the door was closed and an electric shock $(2.0 \mathrm{~mA})$ was delivered to the feet for $5 \mathrm{~s}$. The testing phase to evaluate memory retention commenced $24 \mathrm{~h}$ later. The rat was placed in the light chamber, and the latency time before it entered the dark compartment was measured. If the rat did not enter the dark chamber within a cut-off period of $300 \mathrm{~s}$, a value of $300 \mathrm{~s}$ was used as the latency time.

5-Bromo-2-deoxyuridine Injection and Immunohistochemistry To evaluate the effect of BR003 on cell proliferation in the hippocampus, 5-bromo-2-deoxyuridine (BrdU) uptake was assessed using immunohistochemistry. ${ }^{15)}$ Rats were injected intraperitoneally with $50 \mathrm{mg} / \mathrm{kg}$ BrdU (Sigma, St. Louis, MO, U.S.A.) 14 and $2 \mathrm{~h}$ before they were sacrificed for the preparation of brain tissues. Rats were anesthetized with $50 \mathrm{mg} / \mathrm{kg}$ pentobarbital sodium before being perfused with $4 \%$ paraformaldehyde in $0.1 \mathrm{~m}$ phosphate buffer $(\mathrm{pH}$ 7.4). The brains were removed and post-fixed overnight in the same fixative. Coronal sections $(40 \mu \mathrm{m})$ were then cut with a microtome cryostat (CM3000; Leica, Germany). For immunohistochemical detection of BrdU, every tenth tissue section that contained the DG of the hippocampal formation was selected. Free-floating sections were pretreated with $50 \%$ formamide in $2 \times$ standard saline-citrate at $65^{\circ} \mathrm{C}$ for $2 \mathrm{~h}$ before being incubated at $37^{\circ} \mathrm{C}$ for $30 \mathrm{~min}$ in $2 \mathrm{~N} \mathrm{HCl}$. The sections were rinsed for $10 \mathrm{~min}$ at $25^{\circ} \mathrm{C}$ in $0.1 \mathrm{M}$ boric acid ( $\mathrm{pH}$ 8.5) before being incubated overnight at $25^{\circ} \mathrm{C}$ in primary antibody (Roche Diagnostics, Germany) diluted to $1: 1000$ in phosphate-buffered saline with $0.3 \%$ Triton $\mathrm{X}$ $100,0.5 \mathrm{mg} / \mathrm{ml}$ bovine serum albumin, and $1.5 \%$ normal goat serum. The sections were then incubated with horse antimouse secondary antibody ( $1: 100$; Vector, U.S.A.) for $90 \mathrm{~min}$ and were incubated finally with an avidin-biotin-peroxidase complex (1:100; Vector) for $1 \mathrm{~h}$ at room temperature. The sections were reacted with $0.02 \% 3,3^{\prime}$-diaminobenzidine tetrahydrochloride, $0.01 \% \mathrm{H}_{2} \mathrm{O}_{2}$, and $0.04 \% \mathrm{NiCl}_{2}$ for about $3 \mathrm{~min}$. After each incubation step, the sections were washed three times with phosphate-buffered saline for a total of $15 \mathrm{~min}$. The sections were mounted on gelatin-coated slides and were counterstained with cresyl violet. The number of BrdU-positive cells within the granule cell layer of every tenth section throughout the entire DG was counted under $\times 400$ magnification using Stereo Investigator (MicroBrightField, U.S.A.). The total DG volume was determined using Cavalieri's principle, and the cross-sectional area was

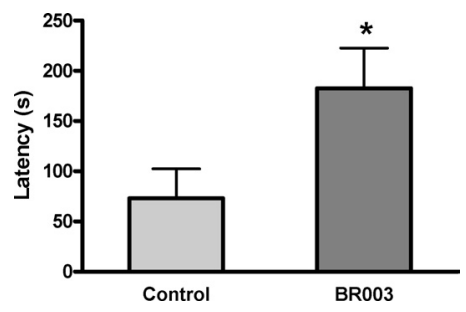

Fig. 1. Effect of BR003 on Response Latency in the Passive Avoidance Test

BR003 refers to the group of rats $(n=11)$ treated orally with an extract of BR003 $(2.0 \mathrm{~g} / \mathrm{kg} / \mathrm{d})$ for $16 \mathrm{~d}$. Controls were administered vehicle alone $(n=11)$. Data are the mean \pm S.E.M. $* p<0.05$ : significantly different from the control group.

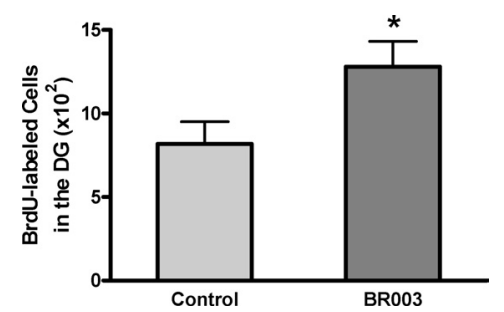

Fig. 2. Effect of BR003 on Cell Proliferation in the Dentate Gyrus of the Rat Hippocampus

BR003 refers to the group of rats $(n=11)$ treated orally with an extract of BR003 $(2.0 \mathrm{~g} / \mathrm{kg} / \mathrm{d})$. Controls were administered vehicle alone $(n=11)$. Data are the number of BrdU-labeled cells per DG expressed as the mean \pm S.E.M. $* p<0.05$ : significantly different from the control group.

measured using an image-analysis system (Multiscan, U.S.A.). ${ }^{16)}$ There were no changes in the volume of the granule cell layer of the DG in any of the experiments. The data are expressed as estimates of the total number of BrdU-positive cells per DG. Following cell counting, each sample was given a coded identification number to allow blind analysis of the data.

Statistical Analysis Raw data from the passive avoidance test were analyzed using the non-parametric MannWhitney test. The immunohistochemistry data were analyzed using Student's $t$-test. All data are expressed as the mean value for the group \pm S.E.M.

\section{RESULTS}

In the passive avoidance test, the mean response latency of the BR003-treated rats $(182.64 \pm 39.88 \mathrm{~s})$ was significantly greater than that of the control rats $(73.08 \pm 29.30 \mathrm{~s})(p<0.05$; Fig. 1). BR003 treatment had no effect on food intake or body weight (data not shown). No detectable irritation, restless, or sedation was observed following the extract or vehicle treatment. Immunohistochemistry revealed that BR003 treatment enhanced cell proliferation within the DG. The BrdU-immunoreactive cells appeared dark and irregular. They were frequently in clusters of two or more and localized within the subgranular zone. These are characteristics of DG precursor cells. The number of BrdU-labeled cells was significantly higher in the BR003-treated group (1281.07 \pm 151.16 cells per DG) than in the control group (818.01 \pm 132.98 cells $)(p<0.05$; Figs. 2,3$)$.

\section{DISCUSSION}

We evaluated the effect of BR003 on memory using a pas- 

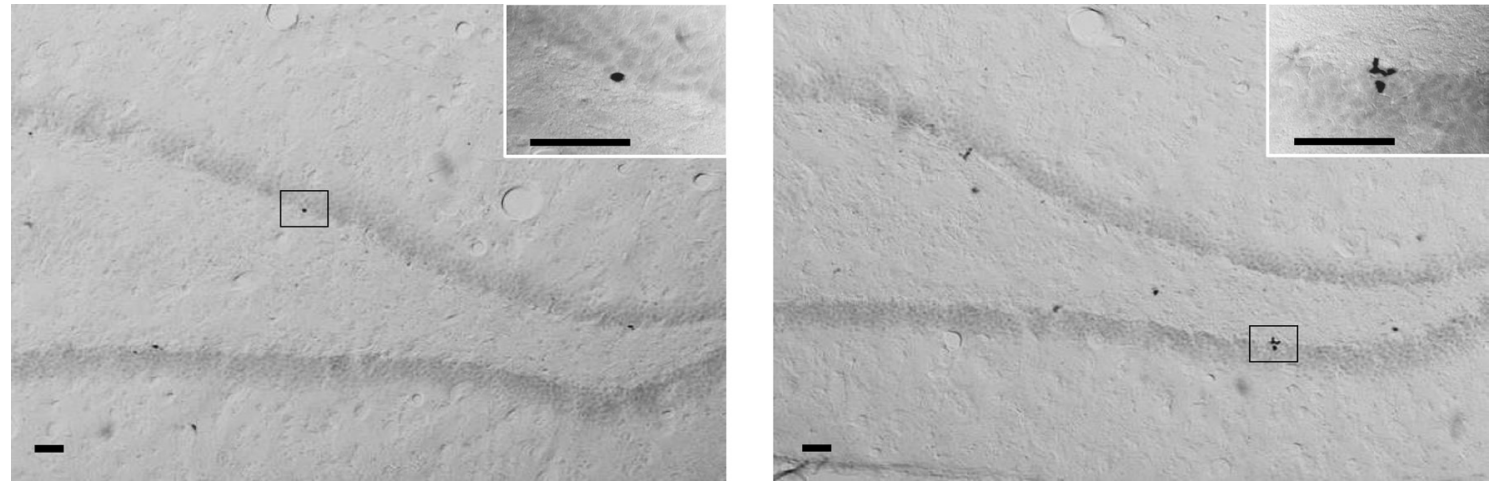

Fig. 3. Effect of BR003 on BrdU Immunoreactivity in the Rat Dentate Gyrus

Representative photographs of the dentate gyrus of a control (left) and a BR003-treated rat (right) are shown. The density of BrdU-labeled cells (black puncta) was greater in the BR003-treated group than in the controls. In the right, BrdU-labeled nuclei clusters are shown. Scale bar $=40 \mu \mathrm{m}$.

sive avoidance test. Passive avoidance tests have been used widely to evaluate the effects of drug administration, lesions, and behavioral manipulations on cognitive functions such as long-term non-spatial memory. The logic is that animals will remember that a particular behavioral response resulted in an unpleasant event, such as an electric shock, and will therefore hesitate to repeat this behavior in future. The consequent increase in the response latency is thought to reflect the strength of the memory trace for the aversive event. ${ }^{17)}$ Dopamine and glutamate are the neurotransmitters that influence passive avoidance most strongly, although GABAergic and cholinergic neurotransmission may also have a relatively weak influence on passive avoidance according to many findings. ${ }^{18)}$ Memory in laboratory animals in the passive avoidance model is improved not only after the administration of drugs such as haloperidol and baclofen but also after the administration of herbal medicines such as Yukmijihwang-tang derivatives and ESP-102. ${ }^{19-22)}$ In the present study, BR003 significantly increased the response latency of rats in the passive avoidance test by up to 2.5 -fold compared with the response of control rats. BR003 includes many herbal medicines that have neural effects. Acanthopanacis Senticosi Radix improves short-term memory in healthy humans. ${ }^{23}$ ) Schizandrae Fructus attenuates the neurotoxicity induced by L-glutamate in primary cultures of rat cortical cells. ${ }^{24}$ Ginkgo Folium has reproducible effects on cognitive functions in patients with Alzheimer's disease and independently improves changes in passive avoidance learning and brain membrane fluidity. ${ }^{25,26)}$ Ginseng Radix restores learning and memory deficits. ${ }^{27)}$ Poria promotes long-term potentiation in the hippocampus. ${ }^{28)}$ Astragali Radix has protective effects against anoxic damage to cultured neurons. ${ }^{29)}$ Polygalae Radix alleviates scopolamine-induced impairment of the passive avoidance response in mice. ${ }^{30)}$ The aforementioned constituents of BR003 may be responsible for the enhancement of memory that we observed. Which neurotransmitter and which of the constituents of BR003 were responsible for the enhancement of memory is yet to be determined.

We also investigated the effect of BR003 on cell proliferation in the DG of the hippocampus using immunohistochemical analysis of BrdU uptake. Our results revealed that the number of BrdU-labeled cells in the BR003-treated group was 1.6-fold greater than that in the control group. Recent studies revealed that the rate of cell proliferation in the DG of rodents can be increased by various factors. Neurotransmitters such as $N$-methyl-D-aspartate (NMDA) glutamate receptor antagonists, serotonin $\left(5-\mathrm{HT}_{1 \mathrm{~A}}\right)$ agonists, and an agonist of dopamine $\left(\mathrm{D}_{2}\right)$-like receptors stimulate the cell proliferation in adult rat DG of hippocampus. ${ }^{31-33)}$ In general, growth factors such as vascular endothelial growth factor and heparin-binding epidermal growth factor have a increasing effect on the adult neurogenesis. ${ }^{34,35)}$ It is reported that hormones such as estrogen stimulate the rate of cell proliferation of the hippocampal subgranular zone. ${ }^{36)}$ Which pathway did the BR003 affect in the cell proliferation is open to discuss and needed further studies.

There are several evidences suggesting that newly generated neurons mature into functional neurons. Newly generated cells within the hippocampus in the adult mouse exhibit a neuronal morphology and can display passive membrane properties, action potentials, and functional synaptic inputs shown in mature dentate granule cells. ${ }^{10)}$ Neuronal progenitor cells are generated in the subgranular zone of the DG and migrate from this region into the granule cell layer of the DG, where the progenitor cells differentiate into neurons and glial cells. ${ }^{37)} \mathrm{A}$ half of new cells generated within the DG in young adult rats can be double-labeled with neuron-specific markers within $5-12 \mathrm{~d}^{38)}$ Neural stem cells from adult hippocampus retain the potential to differentiate into functional neurons with essential properties of mature CNS neurons. ${ }^{39)}$ At this point, BR003 may raise the probability to increase the mature neurons with cognitive function through the stimulating cell proliferation in the DG. To confirm that these cells differentiate into mature neurons, further studies are needed.

In conclusion, our results demonstrate that treatment of rats with BR003 to young adult rats not only improved learning and memory function but also increased cell proliferation in the DG of the hippocampus.

\section{REFERENCES}

1) Izquierdo I., Medina J. H., Izquierdo L. A., Barros D. M., de Souza M M., Mello e Souza T., Neurobiol. Learn. Mem., 69, 219-224 (1998).

2) Zola-Morgan S., Squire L. R., Amaral D. G., J. Neurosci., 6, 2950 2967 (1986).

3) Squire L. R., Psychol. Rev., 99, 195-231 (1992).

4) Cahill L., McGaugh J. L., Trends Neurosci., 21, 294-299 (1998).

5) Altman J., Das G. D., J. Comp. Neurol., 124, 319-335 (1965).

6) Eriksson P. S., Perfilieva E., Bjork-Eriksson T., Alborn A. M., Nord- 
borg C., Peterson D. A., Gage F. H., Nat. Med., 4, 1313-1317 (1998).

7) Kempermann G., Wiskott L., Gage F. H., Curr. Opin. Neurobiol., 14, $186-191$ (2004)

8) Stanfield B. B., Trice J. E., Exp. Brain. Res., 72, 399-406 (1988).

9) Kempermann G., Kuhn H. G., Gage F. H., Nature (London), 386, 493 - 495 (1997).

10) van Praag H., Schinder A. F., Christie B. R., Toni N., Palmer T. D., Gage F. H., Nature (London), 415, 1030-1034 (2002).

11) Nilsson M., Perfilieva E., Johansson U., Orwar O., Eriksson P. S., J. Neurobiol., 39, 569-578 (1999).

12) Bansky D., Barolet R., "Chinese Herbal Medicine Formulas and Strategies," Eastland Press, Seattle, 1990, pp. 3-14.

13) Howes M. J., Houghton P. J., Pharmacol. Biochem. Behav., 75, 513 527 (2003).

14) Izquierdo I., Da Cunha C., Rosat R., Jerusalinski D., Ferreira M. B. C., Medina J. H., Behav. Neural Biol., 58, 16-26 (1992).

15) Park C., Kang M., Kim Y. K., Chung J., Ahn H., Huh Y., Neurosci. Lett., 309, 9-12 (2001).

16) Michel R. P., Cruz-Orive L. M., J. Microsc., 150, 117-136 (1988).

17) Sahgal A., "Behavioural Neuroscience," Oxford University Press, Oxford, 1993 , pp. $49-52$.

18) Myhrer T., Brain Res. Rev., 41, 268-287 (2003).

19) Chugh Y., Saha N., Sankaranarayanan A., Sharma P. L., Methods Find. Exp. Clin. Pharmacol., 13, 161-164 (1991).

20) Georgiev V. P., Yonkov D. I., Kambourova T. S., Neuropeptides, 12, $155-158$ (1988).

21) Rho S., Kang M., Choi B., Sim D., Lee J., Lee E., Cho C., Oh J. W., Park S., Ko S., Shin M., Hong M., Bae H., Biol. Pharm. Bull., 28, 87-93 (2005).

22) Kang S. Y., Lee K. Y., Koo K. A., Yoon J. S., Lim S. W., Kim Y. C., Sung S. H., Life Sci., 76, 1691-1705 (2005).

23) Arushanian E. B., Baida O. A., Mastiagin S. S., Popova A. P., Shikina
I. B., Eksp. Klin. Farmakol., 66, 10-13 (2003).

24) Kim S. R., Lee M. K., Koo K. A., Kim S. H., Sung S. H., Lee N. G., Markelonis G. J., Oh T. H., Yang J. H., Kim Y. C., J. Neurosci. Res., 76, 397-405 (2004).

25) Gertz H. J., Kiefer M., Curr. Pharm., 10, 261-264 (2004).

26) Stoll S., Scheuer K., Pohl O., Muller W. E., Pharmacopsychiatry, 29, 144-149 (1996).

27) Lee S. C., Moon Y. S., You K. H., J. Ethnopharmacol., 69, 1-8 (2000).

28) Smriga M., Saito H., Nishiyama N., Biol. Pharm. Bull., 18, 518-522 (1995).

29) He X., Li C., Yu S., J. Tongji. Med. Univ., 20, 126-127 (2000).

30) Egashira N., Yuzurihara M., Hattori N., Sakakibara I., Ishige A., Phytomedicine, 10, 467-473 (2003).

31) Nacher J., Rosell D. R., Alonso-Llosa G., McEwen B. S., Eur. J. Neurosci., 13, 512-520 (2001).

32) Jacobs B., Tanapat P., Reeves A., Gould E., Soc. Neurosci. Abstr., 24 1992 (1998).

33) Hoglinger G. U., Rizk P., Muriel M. P., Duyckaerts C., Oertel W. H., Caille I., Hirsch E. C., Nat. Neurosci., 7, 726-735 (2004).

34) Jin K., Mao X. O., Sun Y., Xie L., Jin L., Nishi E., Klagsbrun M., Greenberg D. A., J. Neurosci., 22, 5365-5373 (2002).

35) Jin K., Zhu Y., Sun Y., Mao X. O., Xie L., Greenberg D. A., Proc. Natl. Acad. Sci. U.S.A., 99, 11946-11950 (2002).

36) Tanapat P., Hastings N. B., Reeves A. J., Gould E., J. Neurosci., 19, 5792-5801 (1999).

37) Cameron H. A., Woolley C. S., McEwen B. S., Gould E., Neuroscience, 56, 337-344 (1993).

38) Cameron H. A., McKay R. D., J. Comp. Neurol., 435, 406-417 (2001).

39) Song H. J., Stevens C. F., Gage F. H., Nat. Neurosci., 5, 438-445 (2002). 